\title{
Auto-Control Technique Using Gradient Method Based on Radial Basis Function Neural Networks to Control of an Activated Sludge Process of Wastewater Treatment
}

\author{
Abdallah Lemita ${ }^{1}$, Sebti Boulahbel ${ }^{1}$, Sami Kahla $^{2 *}$, Moussa Sedraoui $^{3}$ \\ ${ }^{1}$ Department of Electronics, Faculty of Engineering, University Ferhat Abbas Setif 1, Setif 19000, Algeria \\ ${ }^{2}$ Research Center in Industrial Technologies, CRTI, P.O. Box 64, Cheraga, Algiers 16014, Algeria \\ ${ }^{3}$ Telecommunication Laboratory, University 8 Mai 1945, Guelma 24000, Algeria
}

Corresponding Author Email: samikahla40@yahoo.com

https://doi.org/10.18280/jesa.530510

Received: 20 December 2019

Accepted: 13 September 2020

\section{Keywords:}

activated sludge process, wastewater treatment, gradient descent algorithm, RBF neural network, PI control

\begin{abstract}
Dissolved oxygen (DO) concentration is a key variable in the activated sludge wastewater treatment processes. In this paper, an auto control strategy based on Euler method and gradient method with radial basis function (RBF) neural networks (NNs) is proposed to solve the DO concentration control problem in an activated sludge process of wastewater treatment. The control purpose is to maintain the dissolved oxygen concentration in the aerated tank for having the substrate concentration within the standard limits established by legislation of wastewater treatment. For that reason, a new proposed control strategy based on gradient descent method and RBF neural network has been used. Compared with RBF neural network PI control, the obtained results show the effectiveness in terms of both transient and steady performances of proposed control method for dissolved oxygen control in the activated sludge wastewater treatment processes.
\end{abstract}

\section{INTRODUCTION}

The wastewater treatment process is a very complex process; it presents strong nonlinearity and uncertainties regarding to its parameters. The wastewater treatment comprises various steps used for reducing the contaminants in the wastewater which are: pretreatment, primary treatment, secondary treatment $[1,2]$. The pretreatment has the objective of removing solid objects, and to skimming off floating greases and oils. Without passing the wastewater through the pretreatment, these objects may cause block and damage the equipment and the other steps of treatments. The primary treatment removes the remaining suspended and dissolved solids.

The secondary or biological treatment is the most important step of wastewater treatment. It aims to add microorganisms to reduce the organic matter, nitrogen and phosphorus from the wastewater. There are different methods used in the wastewater treatment process, but the most used and popular one is the activated sludge process (ASP) [3, 4].

In the last years, varieties of researches have been conducted about the control of the level of dissolved oxygen to enhance the process. In general, improvements are related to the controlling techniques. A linear proportional integral (PI) controller with feedforward from the flow rate and the respiration rate has been shown as a basic strategy [4]. Because of the PID controller limitation, the classical method of proportional integral derivative (PID) has been attempted, and the controlling effect of the dissolved oxygen is not satisfactory enough. However, the controllers are normally designed for the particular operational conditions because of the scarcity of sufficient hard or soft sensors and the nonlinear features of the bioprocesses [5]. In recent times, scholars have begun to study the artificial intelligence (AI) technologies which can be widely implemented in numerous areas, including chemical and biochemical processes and. Due to its great capabilities and adaptabilities of nonlinear modelling, the most prevalent AI controlling strategies are neural network and fuzzy network, which are usually integrated with the PID control. A fuzzy method to the control of dissolved oxygen in the process of aeration was studied by Man et al. [6]. An adaptive fuzzy control strategy for dissolved oxygen concentration was used to control of an activated sludge process Liu et al. [7]. In the paper [8] an adaptive fuzzy neural network-based model predictive control (AFNN-MPC) is proposed for the control problem of DO concentration. Piotrowski proposed a supervisory heuristic fuzzy control system applied to a Sequencing Batch Reactor (SBR) in the Wastewater Treatment Plant (WWTP) [9]. Lin and Luo [10] developed an adaptive neural technique using a disturbance observer to solve the dissolved oxygen concentration control problem. An improved multi objective optimal control (MOOC) strategy is developed to improve the operational efficiency, satisfy the effluent quality (EQ) and reduce the energy consumption (EC) in wastewater treatment process [11]. Mirghasemi proposed a robust adaptive neural network control strategy and used it to control the dissolved oxygen in activated sludge process application [12].

In this paper, a control strategy based on Euler method and gradient method with RBF neural network is proposed to control the dissolved oxygen concentration in an activated sludge process of wastewater treatment. The Euler is a numerical method that is used to approximate the solution of a nonlinear differential equation (nonlinear system), and the gradient descent algorithm and the RBF neural network are used to find the values of a function's parameters (coefficients) that minimize a performance function as possible. The performance of the proposed control strategies laws is 
illustrated with numerical simulations comparing their results with RBFNN-PI controller.

The remainder of this paper is organized as follows: in Section 2, Euler method is clearly discussed, in Section 3, presents a nonlinear control strategy based on gradient method accompanied with neural network method. In Section 4, RBF neural network PI control is discussed. The Section 5, a mathematical model of wastewater treatment process is given. In Section 6, the simulation results are presented. Finally, it is ended by a conclusion.

\section{EULER METHOD}

The Euler's method is numerical method that is used to approximate the solutions of a differential equation (Figure 1). Let consider the following differential equation:

$$
\frac{\partial y(t)}{\partial t}=f(t, y(t))
$$

$\forall t \in \mathfrak{R}, y(0)=y_{0}$ is the initial condition.

t: time variable, $y$ : output system.

The principal of Euler's method is to integrate the two parts of Eq. (1) between $t_{0}$ and $t_{1}$

$$
\begin{aligned}
& \int_{t_{0}}^{t_{1}} \frac{\partial y(t)}{\partial t} d t=\int_{t_{0}}^{t_{1}} f(t, y(t)) d t \\
& y\left(t_{1}\right)=y\left(t_{0}\right)+\int_{t_{0}}^{t_{1}} f(t, y(t)) d t
\end{aligned}
$$

The integral $\int_{t_{0}}^{t_{1}} f(t, y(t)) d t$ can be approximated by:

* The area of upper rectangle of $f\left(t_{0}, y\left(t_{0}\right)\right)$ and length $t_{1}-t_{0}=h$. Then:

$$
\int_{t_{0}}^{t_{1}} f(t, y(t)) d t \approx h \cdot f\left(t_{0}, y\left(t_{0}\right)\right)
$$

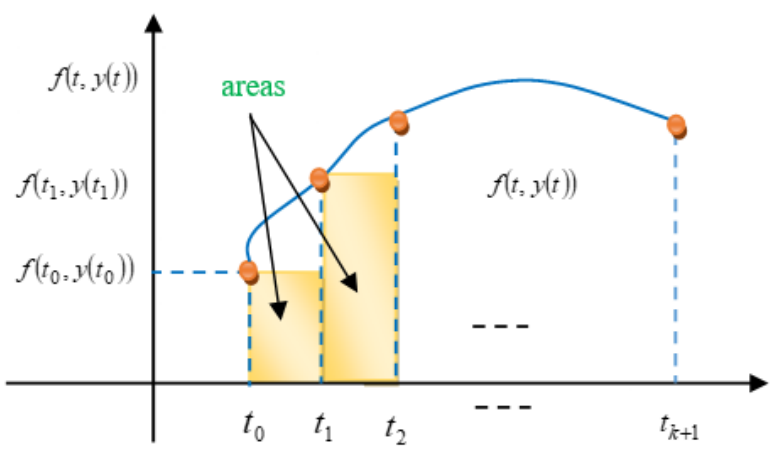

Figure 1. Euler method

* The area of upper rectangle of $f\left(t_{1}, y\left(t_{1}\right)\right)$ and length $t_{1}-t_{0}=h$. Then:

$$
\int_{t_{0}}^{t_{1}} f(t, y(t)) d t \approx h \cdot f\left(t_{1}, y\left(t_{1}\right)\right)
$$

* The following statement results from the application of the trapezoidal rule in the approximation integration of the integral in Eq. (2).

$$
\int_{t_{0}}^{t_{1}} f(t, y(t)) d t \approx \frac{h}{2} \cdot\left(f\left(t_{0}, y\left(t_{0}\right)\right)+f\left(t_{1}, y\left(t_{1}\right)\right)\right)
$$

By using Eq. (4), The numerical solution of Eq. (1) can be given by the following equation:

$$
y\left(t_{1}\right)=y\left(t_{0}\right)+h . f\left(t_{0}, y\left(t_{0}\right)\right)
$$

For $k \geq 0$

$$
y\left(t_{k+1}\right)=y\left(t_{k}\right)+h \cdot f\left(t_{k}, y\left(t_{k}\right)\right)
$$

Now, consider a nonlinear system that can be written as the following differential equation:

$$
\frac{\partial y_{u}(t)}{\partial t}=f\left(t, y_{u}(t), u(t)\right)
$$

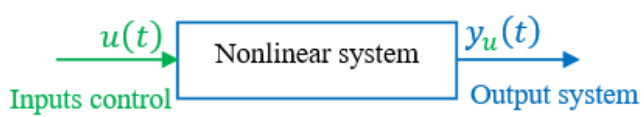

Figure 2. Nonlinear system with single input-single output

The curve of the output system $y_{u}\left(t_{k}\right)$ depends on the input control $\mathrm{u}(\mathrm{t})$. If we consider two different inputs control $\mathrm{u}(\mathrm{t})=\mathrm{u}_{0}$, and $\mathrm{u}(\mathrm{t})=\mathrm{u}_{1}$, then Eq. (9) yields:

$$
\begin{aligned}
& \frac{\partial y_{u_{0}}(t)}{\partial t}=f\left(t, y_{u_{0}}(t), u_{0}\right) \\
& \frac{\partial y_{u_{1}}(t)}{\partial t}=f\left(t, y_{u_{1}}(t), u_{1}\right)
\end{aligned}
$$

The numerical solutions of these equations (Eq. (10) and Eq. (11)) by using Euler's method are:

$$
\begin{gathered}
y_{u_{0}}\left(t_{k+1}\right)=y_{u_{0}}\left(t_{k}\right)+h \cdot f\left(t_{k}, y_{u_{0}}\left(t_{k}\right), u_{0}\right) \\
y_{u_{1}}\left(t_{k+1}\right)=y_{u_{1}}\left(t_{k}\right)+h \cdot f\left(t_{k}, y_{u_{1}}\left(t_{k}\right), u_{1}\right)
\end{gathered}
$$

Figure 3 shows the curves of Eq. (12) and Eq. (13).

Figure 3 shows that if we apply two different inputs $u(t)=u_{0}$ and $\mathrm{u}(\mathrm{t})=\mathrm{u}_{1}$ on system in Figure 2, we will have two different trajectories in the output system. Suppose that we know the input $\mathrm{u}(\mathrm{t})=\mathrm{u}_{0}$, if we want that the trajectory $y_{u_{0}}\left(t_{k+1}\right)$ (blue curve) tracks the trajectory $y_{u_{1}}\left(t_{k+1}\right)$ (red curve), we have to find the value of input control $\mathrm{u}_{1}$ that makes the trajectory $y_{u_{0}}$ tracks the trajectory $y_{u_{1}}$. 
The aim of the proposed control strategy is to control the system output $y_{u_{0}}\left(t_{k+1}\right)$ to track a desired reference $r\left(t_{k+1}\right)$ by changing at every instant $t_{k}$ the value of input control $u_{k}$.

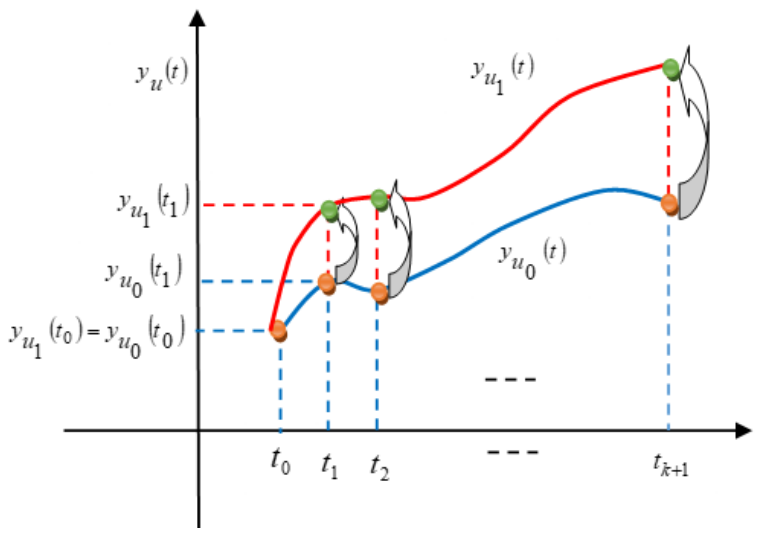

Figure 3. Curve of Eq. (9) with two different inputs control $u(t)=u_{0}$ and $u(t)=u_{1}$

\section{GRADIENT DESCENT ALGORITHM BASED ON RBF NEURAL NETWORK}

The proposed control strategy is depicted in Figure 4.

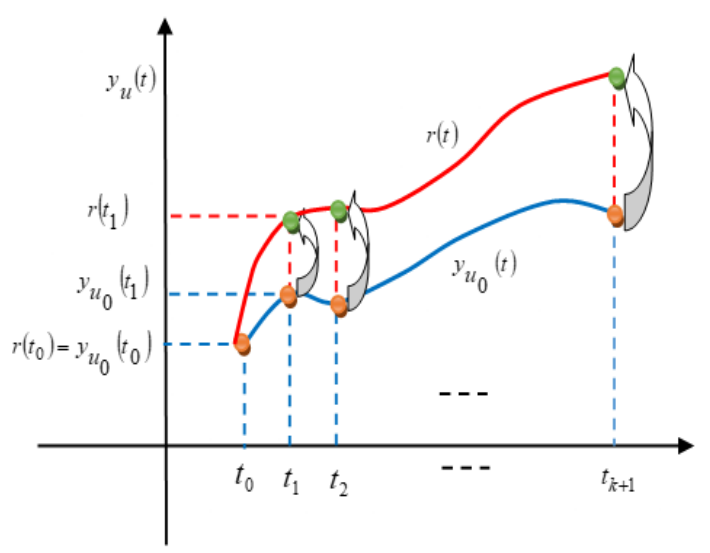

Figure 4. Curve of Principal of the proposed control strategy

Consider the following nonlinear system:

$$
\frac{\partial y_{u_{0}}(t)}{\partial t}=f\left(t, y_{u_{0}}(t), u_{0}\right)
$$

The numerical solution of Eq. (14) by using Euler's method is:

$$
y_{u_{0}}\left(t_{1}\right)=y_{u_{0}}\left(t_{0}\right)+h . f\left(t_{0}, y_{u_{0}}\left(t_{0}\right), u_{0}\right)
$$

At time $t_{1}$, we have to find the value of the input control $u_{1}$ to get: $y_{u_{0}}\left(t_{1}\right)=r\left(t_{1}\right)$.

$$
y_{u_{1}}\left(t_{1}\right)=y_{u_{0}}\left(t_{0}\right)+h . f\left(t_{0}, y_{u_{0}}\left(t_{0}\right), u_{1}\right)
$$

The input control $\mathrm{u}_{1}$ is adjusted by using the gradient descent algorithm by minimizing the performance function with respect to $\mathrm{u}_{0}$. The performance function is the squared error $E\left(t_{1}\right)$ between $y_{u_{1}}\left(t_{1}\right)$ and $y_{u_{0}}\left(t_{1}\right)$.

$$
\begin{gathered}
E\left(t_{1}\right)=\frac{1}{2}\left(e\left(t_{1}\right)\right)^{2}=\frac{1}{2}\left(y_{u_{1}}\left(t_{1}\right)-y_{u_{0}}\left(t_{1}\right)\right)^{2} \\
E\left(t_{1}\right)=\frac{1}{2}\left(r\left(t_{1}\right)-y_{u_{0}}\left(t_{1}\right)\right)^{2}
\end{gathered}
$$

Input control $\mathrm{u}_{1}$ updating by using the gradient descent algorithm:

$$
\begin{gathered}
u_{1}=u_{0}+\Delta u_{0} \\
\Delta u_{0}=-\lambda \cdot \frac{\partial E\left(t_{1}\right)}{\partial u_{0}}
\end{gathered}
$$

Then:

$$
u_{1}=u_{0}-\lambda \cdot \frac{\partial E\left(t_{1}\right)}{\partial u_{0}}
$$

where, $\lambda$ : learning rate.

$$
\begin{gathered}
u_{1}=u_{0}-\lambda \cdot \frac{\partial E\left(t_{1}\right)}{\partial y_{u_{0}}\left(t_{1}\right)} \cdot \frac{\partial y_{u_{0}}\left(t_{1}\right)}{\partial f\left(t_{0}, y_{u_{0}}\left(t_{0}\right), u_{0}\right)} \cdot \frac{\partial f\left(t_{0}, y_{u_{0}}\left(t_{0}\right), u_{0}\right)}{\partial u_{0}} \\
u_{1}=u_{0}+\lambda \cdot e\left(t_{1}\right) \cdot h \cdot \frac{\partial f\left(t_{0}, y_{u_{0}}\left(t_{0}\right), u_{0}\right)}{\partial u_{0}} \\
u_{1}=u_{0}+\lambda \cdot e\left(t_{1}\right) \cdot \frac{\partial y_{u_{0}}\left(t_{1}\right)}{\partial u_{0}}
\end{gathered}
$$

In general case, it is difficult to calculate the expression of $\frac{\partial y_{u_{0}}\left(t_{1}\right)}{\partial u_{0}}$, therefore, it has been known that the neural network can approximate any nonlinear function, then, it can be used to approximate $\frac{\partial y_{u_{0}}\left(t_{1}\right)}{\partial u_{0}}$.

\subsection{RBF neural network algorithm}

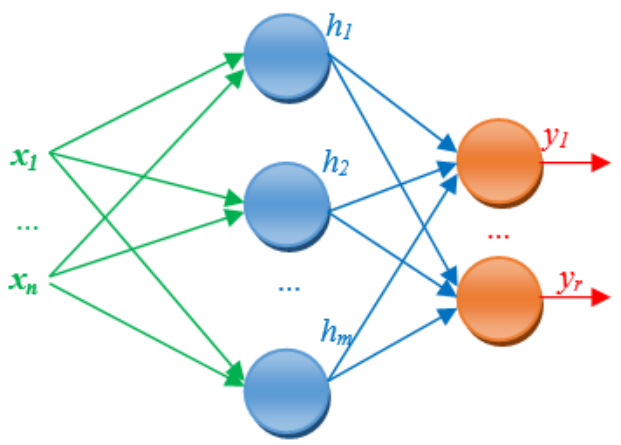

Figure 5. RBF neural network structure 
A radial basis function neural network (RBFNN) is introduced into neural network in the paper [13], it has three layers: an input layer, a nonlinear hidden layer that uses Gaussian function as activation function, and a linear output layer [14]. The RBF networks have many uses, including function approximation, classification, and system control. It has the advantage of fast learning speed and is able to avoid the problem of local minimum.

The structure of the RBF neural network is illustrated in Figure 5.

The output of the $j^{\text {th }}$ hidden neurons is given by the following equation:

$$
h_{j}=\exp \left(-\frac{\left\|X-C_{i, j}\right\|^{2}}{2 b_{j}^{2}}\right)
$$

where, $X=\left[x_{1}, x_{2}, \ldots, x_{n}\right]^{T}$ is the input vector of the neural network.

The RBF neural network output is described in the following equation:

$$
y_{\text {RBFNN }}=\sum_{j=1}^{m} W_{l, j} h_{j}=\sum_{j=1}^{m} W_{l, j} \exp \left(-\frac{\left\|X-C_{i, j}\right\|^{2}}{2 b_{j}^{2}}\right)
$$

where, $W_{l, j}$ is the weight between the hidden layer and the output layer. The center $C_{i, j}$, the basis width parameter $b_{j}$ and the weights $W_{l, j}$ of the RBF neuron network are adjusted by using the gradient descent algorithm to minimize the sum of square error $E_{R B F N N \text {. }}$

The expression of $E_{R B F N N}$ is given as follow:

$$
\begin{gathered}
E_{R B F N N}=\frac{1}{2} \sum\left(e_{R B F N N}(k)\right)^{2}=\frac{1}{2} \sum_{k=1}^{r}\left(y_{u_{k}}(k)-y_{R B F N N}(k)\right)^{2} \\
C_{i, j}(k)=C_{i, j}(k-1)+\Delta C_{i, j}+\alpha\left(C_{i, j}(k-1)-C_{i, j}(k-2)\right) \\
b_{j}(k)=b_{j}(k-1)+\Delta b_{j}+\alpha\left(b_{j}(k-1)-b_{j}(k-2)\right) \\
W_{l, j}(k)=W_{l, j}(k-1)+\Delta W_{l, j}+\alpha\left(W_{l, j}(k-1)-W_{l, j}(k-2)\right)
\end{gathered}
$$

The corresponding modifier formulas are as follows:

$$
\begin{gathered}
\Delta C_{i, j}=-\eta \frac{\partial E_{R B F N N}}{\partial C_{i, j}}=-\eta \frac{\partial E_{R B F N N}}{\partial y_{R B F N N}} \frac{\partial y_{R B F N N}}{\partial h_{j}} \frac{\partial h_{j}}{\partial C_{i, j}} \\
\Delta C_{i, j}=\eta \cdot e_{R B F} W_{l, j} h_{j} \cdot\left(\frac{X-C_{i, j}}{b_{j}^{2}}\right) \\
\Delta b_{j}=-\eta \frac{\partial E_{R B F N N}}{\partial b_{j}}=-\eta \frac{\partial E_{R B F N N}}{\partial y_{R B F N N}} \frac{\partial y_{R B F N N}}{\partial h_{j}} \frac{\partial h_{j}}{\partial b_{j}} \\
\Delta b_{j}=\eta \cdot e_{R B F N N} W_{l, j} h_{j} \frac{\left\|X-C_{i, j}\right\|^{2}}{b_{j}^{3}}
\end{gathered}
$$

$$
\begin{gathered}
\Delta W_{l, j}=-\eta \frac{\partial E_{R B F N N}}{\partial W_{l, j}}=-\eta \frac{\partial E_{R B F N N}}{\partial y_{R B F N N}} \frac{\partial y_{R B F N N}}{\partial W_{l, j}} \\
\Delta W_{l, j}=\eta \cdot e_{R B F N N} \cdot h_{j}
\end{gathered}
$$

where, $\alpha$ is the momentum factor, and $\eta$ is the learning rate. From Eq. (24), we have:

$$
u_{1}=u_{0}+\lambda \cdot e\left(t_{1}\right) \cdot \frac{\partial y_{u_{0}}\left(t_{1}\right)}{\partial u_{0}}
$$

The RBF neural network will be used to calculate the expression of $\frac{\partial y_{u_{0}}\left(t_{1}\right)}{\partial u_{0}}$.

The schema of RBF neural network identification is depicted in Figure 6.

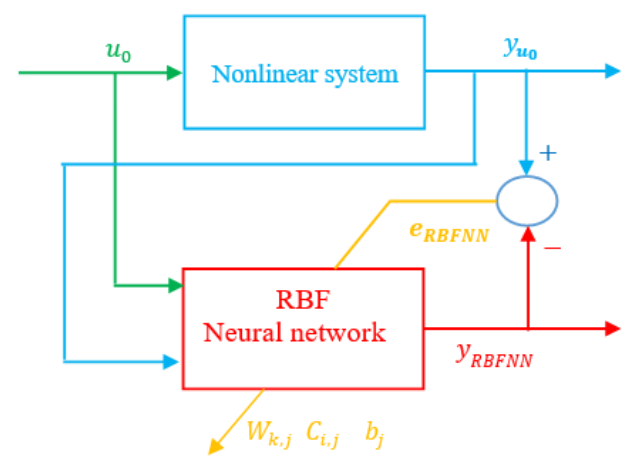

Figure 6. Schema of RBF neural network identification

If the RBF neural network output $y_{R B F N N}$ is equal to the system output $y_{u_{0}}[15,16]$, then, we can use the expression of $y_{R B F N N}$ to calculate the expression of $\frac{\partial y_{u_{0}}\left(t_{1}\right)}{\partial u_{0}}$.

$$
\frac{\partial y_{u_{0}}\left(t_{1}\right)}{\partial u_{0}} \approx \frac{\partial y_{R B F N N}}{\partial u_{0}}=\frac{\partial}{\partial u_{0}} \sum_{j=1}^{r} W_{1, j} h_{j}
$$

$$
\frac{\partial y_{u_{0}}\left(t_{1}\right)}{\partial u_{0}}=\frac{\partial}{\partial u_{0}} \sum_{j=1}^{r} W_{1, j} \exp \left(-\frac{\left\|X-C_{i, j}\right\|^{2}}{2 b_{j}^{2}}\right)
$$

$$
\begin{gathered}
\frac{\partial y_{u_{0}}\left(t_{1}\right)}{\partial u_{0}}=\sum_{j=1}^{r} W_{1, j} \frac{\partial}{\partial u_{0}} \exp \left(-\frac{\left\|X-C_{i, j}\right\|^{2}}{2 b_{j}^{2}}\right) \\
\frac{\partial y_{u_{0}}\left(t_{1}\right)}{\partial u_{0}}=\sum_{j=1}^{r} W_{1, j} \frac{\partial}{\partial x_{1}} \\
\exp \left(-\frac{X^{T} X-X^{T} C_{i, j}-C_{i, j}^{T} X+C_{i, j}^{T} C_{i, j}}{2 b_{j}^{2}}\right)
\end{gathered}
$$

With: $X=\left[\begin{array}{ll}u_{0} & y_{u_{0}}\end{array}\right]^{T}=\left[\begin{array}{ll}x_{1} & x_{2}\end{array}\right]^{T}$ 


$$
\begin{aligned}
& C_{i, j}= {\left[\begin{array}{llll}
C_{1,1} & C_{1,2} & \ldots & C_{1, m} \\
C_{2,1} & C_{2,2} & \ldots & C_{2, m}
\end{array}\right] } \\
& \frac{\partial y_{u_{0}}\left(t_{1}\right)}{\partial u_{0}}=\sum_{j=1}^{r} W_{1, j} \frac{\partial}{\partial x_{1}} \exp \\
&\left(\begin{array}{cc}
{\left[\begin{array}{ll}
x_{1} & x_{2}
\end{array}\right]\left[\begin{array}{l}
x_{1} \\
x_{2}
\end{array}\right]-\left[\begin{array}{ll}
x_{1} & x_{2}
\end{array}\right] C_{i, j}-C_{i, j}^{T}\left[\begin{array}{l}
x_{1} \\
x_{2}
\end{array}\right]+C_{i, j}^{T} C_{i, j}} \\
2 b_{j}^{2}
\end{array}\right) \\
& \\
& \frac{\partial y_{u_{0}}\left(t_{1}\right)}{\partial u_{0}}=\sum_{j=1}^{r} W_{1, j} \frac{\partial}{\partial x_{1}} \exp \\
&\left(-\frac{x_{1}^{2}+x_{2}^{2}-2 x_{1} C_{1, j}-2 x_{2} C_{2, j}^{T}+C_{i, j}^{T} C_{i, j}}{2 b_{j}^{2}}\right) \\
& \frac{\partial y_{u_{0}}\left(t_{1}\right)}{\partial u_{0}}=\sum_{j=1}^{r} W_{1, j}\left(\frac{C_{1, j}-x_{1}}{b_{j}^{2}}\right) \cdot \exp \\
&\left(-\frac{x_{1}^{2}+x_{2}^{2}-2 x_{1} C_{1, j}-2 x_{2} C_{2, j}^{T}+C_{i, j}^{T} C_{i, j}}{2 b_{j}^{2}}\right)
\end{aligned}
$$

So:

$$
\frac{\partial y_{u_{0}}\left(t_{1}\right)}{\partial u_{0}}=\sum_{j=1}^{r} W_{1, j}\left(\frac{C_{1, j}-x_{1}}{b_{j}^{2}}\right) \cdot h_{j}
$$

We substitute Eq. (45) in Eq. (37) to get the control law:

$$
u_{1}=u_{0}+\lambda . e\left(t_{1}\right) \cdot \sum_{j=1}^{r} W_{1, j}\left(\frac{C_{1, j}-x_{1}}{b_{j}^{2}}\right) \cdot h_{j}
$$

The steps of the proposed control strategy are as follows:

Step1. We start by $u=u_{0}$ (the choice of $u_{0}$ depend on the study system).

Step2. Initializing the network parameters: the number of nodes in input, hidden and output layer, the center $C_{i, j}$, the basis width parameter $b_{j}$ and the weights $W_{l, j}$, learning rate.

Step3. for $k \geq 0$.

- Calculating the output $y_{u_{k}}\left(t_{k+1}\right)$ and network output $y_{R B F N N}\left(t_{k+1}\right)$, calculating the error $e_{R B F N N}\left(t_{k+1}\right)$.

- Adjusting of neural network parameters: $C_{i, j}, b_{j}$ and $W_{l, j}$ from Eq. (32), Eq. (34) and Eq. (36).

- Calculating error $e\left(t_{k+1}\right)$ between $y_{u_{k}}\left(t_{k+1}\right)$ and $r\left(t_{k+1}\right)$.

- Calculating the new value of $u_{k+1}$ via the following expression:

$$
u_{k+1}=u_{k}+\lambda \cdot e\left(t_{k+1}\right) \cdot \sum_{j=1}^{r} W_{1, j}\left(\frac{C_{1, j}-u_{k}}{b_{j}^{2}}\right) \cdot h_{j}
$$

Step 4. We replace the found value of $u_{k+1}$ on the system.

$$
y_{u_{0}}\left(t_{k+1}\right)=y_{u_{0}}\left(t_{k}\right)+h . f\left(t_{k}, y_{u_{0}}\left(t_{k}\right), u_{k+1}\right)
$$

According to this algorithm, we can obtain: $y_{u_{0}}\left(t_{k+1}\right)=r\left(t_{k+1}\right)$.

The structure of the proposed method is illustrated in Figure 7.

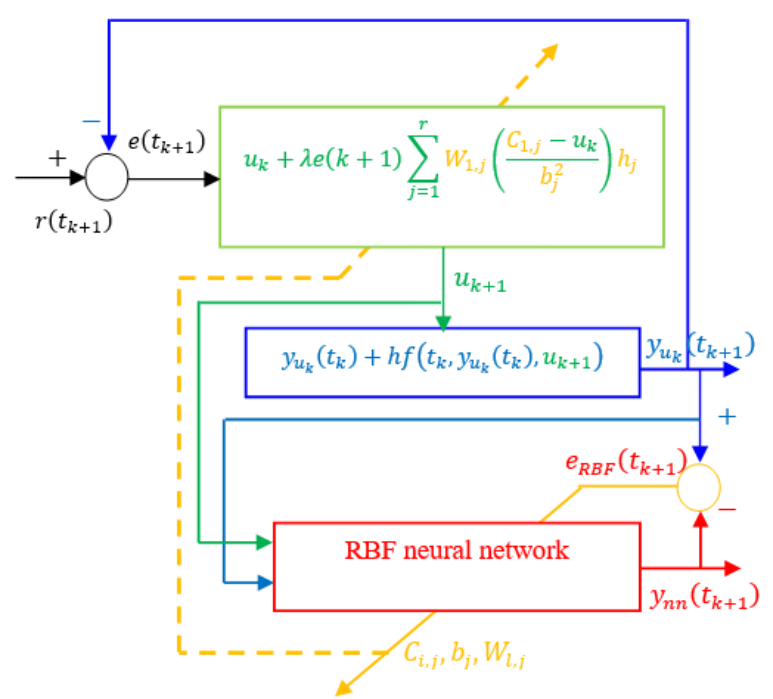

Figure 7. Schema of the proposed control strategy

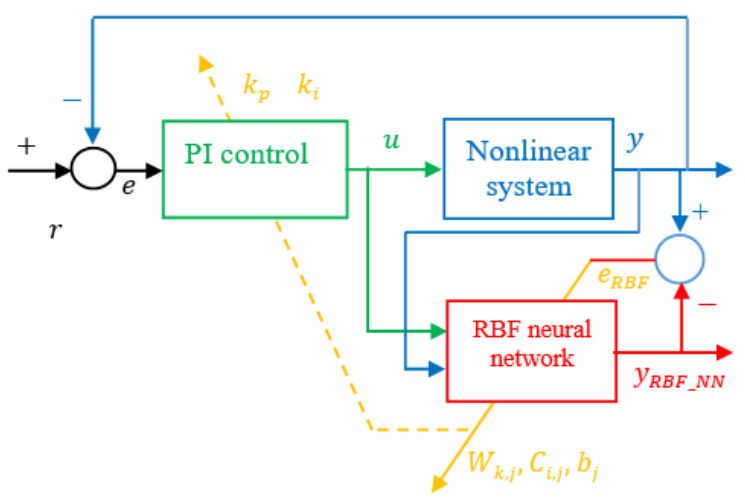

Figure 8. Adaptive RBF neural network PI structure

\section{STRUCTURE OF RBF NEURAL NETWORK PI CONTROL}

The structure of the RBF neural network PI is based on two control strategy (Figure 8), the first one is a conventional PI control because of its good control performance and the second is the RBF neural network control strategy. The PI control is used for controlling the dissolved oxygen concentration in the aerobic reactor, and the RBF neural network is used to regulate the parameters of PI control: $k_{p}$ and $\mathrm{k}_{\mathrm{i}}$ for improving the adaptability of the controller.

The mathematical expression of the PI (Proportional Integral) control algorithm is given by the following equation:

$$
u(k)=u(k-1)+k_{p}(e(k)-e(k-1))+k_{i} e(k)
$$

where, $u(k)$ is the output of the PI control (the input control of the system) and $e$ is the error between the desired output $r$ and actual system output.

$$
e(k)=r(k)-y(k)
$$


It has been known that the PI control performance is based on the value of PI parameters $k_{p}$ and $k_{i}$. To improve the performance of the PI controller against the disturbance on the system, the parameters $k_{p}$ and $k_{i}$ can be auto-adjusted and optimized, so, the adaptive PI control algorithm became:

$$
u(k)=u(k-1)+k_{p}(k)(e(k)-e(k-1))+k_{i}(k) e(k)
$$

The parameters of PI controller $\left(k_{p}\right.$ and $\left.k_{i}\right)$ are adjusted (auto-tuning) by using the gradient descent algorithm to minimize the sum of squared error $\mathrm{E}$ between the system output $y$ and the desired output $r$.

The performance function $\mathrm{E}$ is defined as:

$$
E(k)=\frac{1}{2} \sum_{k=1}^{N}(r(k)-y(k))^{2}=\frac{1}{2} \sum_{k=1}^{N}(e(k))^{2}
$$

According to the gradient descent method, the adjustment rules of the PI parameters are given as:

$$
\begin{gathered}
k_{p}(k)=k_{p}(k-1)+\Delta k_{p} \\
k_{i}(k)=k_{i}(k-1)+\Delta k_{i}
\end{gathered}
$$

where,

$$
\begin{gathered}
\Delta k_{p}=-\eta \frac{\partial E}{\partial k_{p}}=-\eta \frac{\partial E}{\partial y} \frac{\partial y}{\partial u} \frac{\partial u}{\partial k_{p}}=\eta e(k) \frac{\partial y}{\partial u}(e(k)-e(k-1)) \\
\Delta k_{i}=-\eta \frac{\partial E}{\partial k_{i}}=-\eta \frac{\partial E}{\partial y} \frac{\partial y}{\partial u} \frac{\partial u}{\partial k_{i}}=\eta e(k) \frac{\partial y}{\partial u} e(k)
\end{gathered}
$$

where,

$$
\frac{\partial y}{\partial u}=\sum_{j=1}^{r} W_{1, j}\left(\frac{C_{1, j}-x_{1}}{b_{j}^{2}}\right) \cdot h_{j}
$$

\section{MATHEMATICAL MODEL OF WASTEWATER TREATMENT PROCESS}

The schematic of the wastewater treatment process is represented in Figure 9.

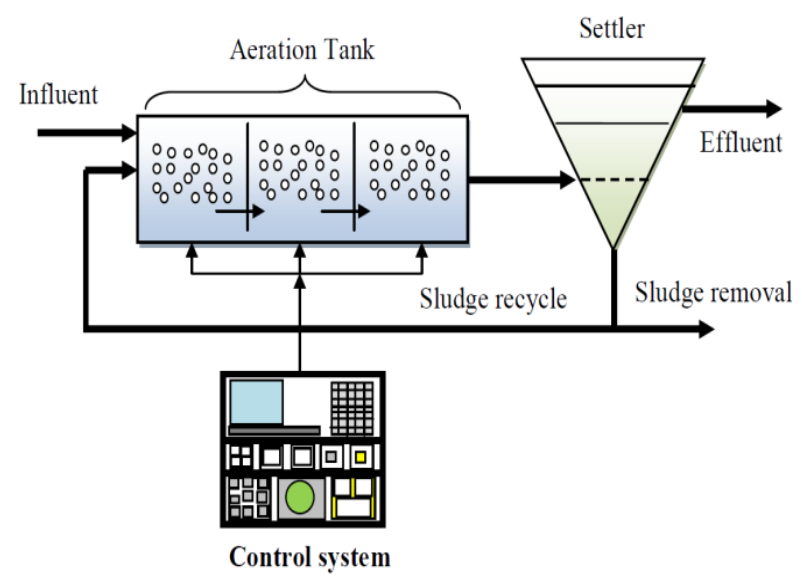

Figure 9. Schema of activated sludge process
The aeration tank is a biological reactor in which the microorganisms are developed by removing the organic substrate in the presence of the dissolved oxygen concentration. In the settler tank the solids are separated from the wastewater. The growth of micro-organisms (biomass) in the aeration tank is not sufficient, then, a part of the removed sludge (the sludge contains the biomass) is recycled back tothe aeration tank while the other part is removed from the system.

The mathematical model considered in this paper contains four differential equations, the biomass concentrationX, the substrate concentration $\mathrm{S}$, the dissolved oxygen concentration $\mathrm{DO}$ and the recycled biomass concentration $\mathrm{X}_{\mathrm{r}}$. The model is given by the following equations $[17,18]$.

$$
\begin{gathered}
\frac{\partial X(t)}{\partial t}=\mu(t) \cdot X(t)-D \cdot(1+r) \cdot X(t)+r \cdot D \cdot X_{r}(t) \\
\frac{\partial S(t)}{\partial t}=-\frac{1}{Y} \mu(t) \cdot X(t)-D \cdot(1+r) \cdot S(t)+D \cdot S_{i n} \\
\frac{\partial D O(t)}{\partial t}=-\frac{K_{0}}{Y} \mu(t) \cdot X(t)-D \cdot(1+r) \cdot D O(t)+ \\
K L a \cdot\left(D O_{\max }-D O(t)\right)+D \cdot D O_{i n} \\
\frac{\partial X_{r}(t)}{\partial t}=D \cdot(1+r) \cdot X(t)-D \cdot(\beta+r) \cdot X_{r}(t)
\end{gathered}
$$

\begin{tabular}{|c|c|c|c|}
\hline Description & Parameters & Units & Values \\
\hline Biomass yield factor & $Y_{h}$ & - & 0.65 \\
\hline $\begin{array}{l}\text { Maximum specific growth } \\
\text { rate }\end{array}$ & $\mu_{\max }$ & $h^{-1}$ & 0.15 \\
\hline $\begin{array}{l}\text { Half-saturation coefficient } \\
\text { for micro-organisms }\end{array}$ & $k s$ & $m g . l^{-1}$ & 100 \\
\hline $\begin{array}{l}\text { Oxygen half-saturation } \\
\text { coefficient for } \\
\text { micro-organisms }\end{array}$ & $k_{D O}$ & $m g . l^{-1}$ & 2 \\
\hline Maximum DO concentration & $D O_{\max }$ & $m g . l^{-1}$ & 10 \\
\hline Model constant & $K_{0}$ & - & 0.5 \\
\hline Oxygen transfer rate & $\alpha$ & - & 0.018 \\
\hline Ratio of recycled & $r$ & - & 0.6 \\
\hline Ratio of waste flow & $\beta$ & - & 0.2 \\
\hline $\begin{array}{l}\text { Influent substrate } \\
\text { concentration }\end{array}$ & $\operatorname{Sin}$ & $m g . l^{-1}$ & 200 \\
\hline Influent DO concentration & DOin & $m g . l^{-1}$ & 0.5 \\
\hline $\begin{array}{l}\text { Oxygen mass transfer } \\
\text { coefficient }\end{array}$ & $K L a$ & $h^{-1}$ & - \\
\hline Aeration rate & $W$ & $m^{3} \cdot h^{-1}$ & - \\
\hline Dilution rate & $D$ & $h^{-1}$ & - \\
\hline
\end{tabular}

With:

$$
\begin{gathered}
\mu(t)=\mu_{\max } \cdot \frac{S(t)}{S(t)+k_{s}} \cdot \frac{D O(t)}{D O(t)+k_{D O}} \\
K L a=\alpha \cdot W(k) .
\end{gathered}
$$

$W$ : the aeration flow rate.

The aeration rate $\mathrm{W}$ is considered in this paper as the variable control for controlling the oxygen concentration in the aeration tank. Table 2 and Table 3 below show the parameters and initial values of the model respectively.

Table 2. Model parameters 
Table 3. Initial values

\begin{tabular}{c|ccc}
\hline Variables concentrations & Symbols & Units & Values \\
\hline Substrate concentration & $S s$ & $m g . l^{-1}$ & 88 \\
Biomass concentration & $X$ & $m g . l^{-1}$ & 20 \\
$\begin{array}{c}\text { Dissolved oxygen } \\
\text { concentration }\end{array}$ & $D O$ & $m g . l^{-1}$ & 2 \\
$\begin{array}{c}\text { Recycle biomass } \\
\text { concentration }\end{array}$ & $X r$ & $m g . l^{-1}$ & 320 \\
\hline
\end{tabular}

\section{RESULTS AND DISCUSSION}

This paper proposes a control strategy based on Euler and gradient method based on Radial basis function neural network (RBFNN) is used to control the organic substances concentration in the aeration tank through the control of the dissolved oxygen concentration.

Figures 10 and 11 show the dissolved oxygen and substrate concentration in open loop (no control technique is applied to control the dissolved oxygen concentration). We can see clearly that the substrate concentration exceeds the maximum allowable value $20 \mathrm{mg} \mathrm{l}^{-1}$, so, the control of the dissolved oxygen concentration became obligatory for having a substrate concentration below the standard limit.

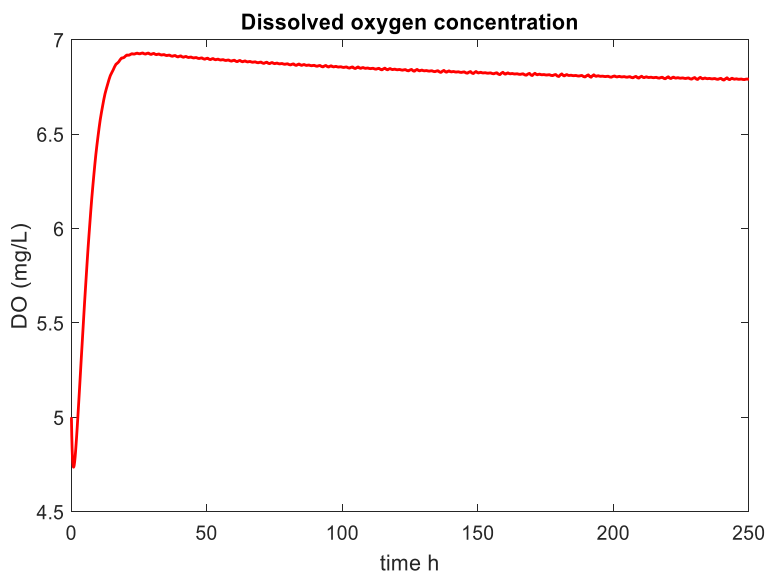

Figure 10. Dissolved oxygen concentration

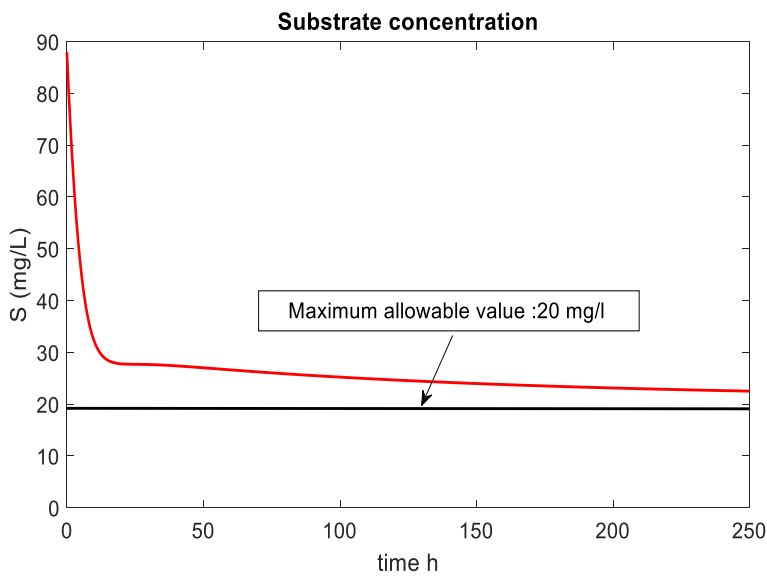

Figure 11. Substrate concentration

For comparison, RBF neural network PI controller has been used with the initial's parameters: $k_{p}=3$ and $k_{i}=0.9$.

The RBF neural network has the following structure (for the proposed control strategy and RB neural network PI control): two inputs in input layer $X=[W D O]^{T}$, six neurons in hidden layer, and one neuron in output layer. The RBF neural network parameters $C_{i, j}, b_{j}$ and $W_{k, j}$ are respectively initialized in the range $[30,60],[20,40]$, and $[0,10]$, the learning rate $\mu=0.09$ and he momentum factor $\alpha=0.5$.

The step size $\mathrm{h}=0.5$.

The dilution rate (Figure 12) is considered variable to cover many different regimes: high flow $\mathrm{D}=0.035 \mathrm{~h}^{-1}$, normal flow $\mathrm{D}=0.025 \mathrm{~h}^{-1}$ and low flow $\mathrm{D}=0.015 \mathrm{~h}^{-1}$. The influent substrate concentration $S_{\text {in }}$ is also considered with different values to assure a real study of wastewater system (Figure 13).

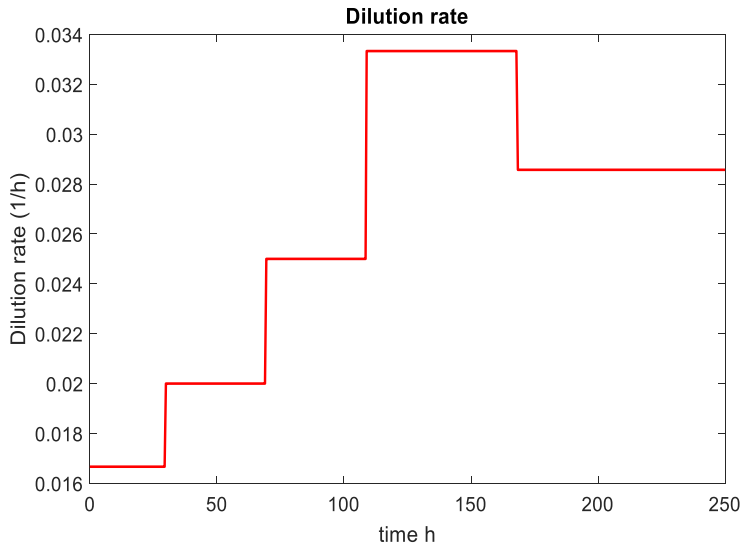

Figure 12. Dilution rate

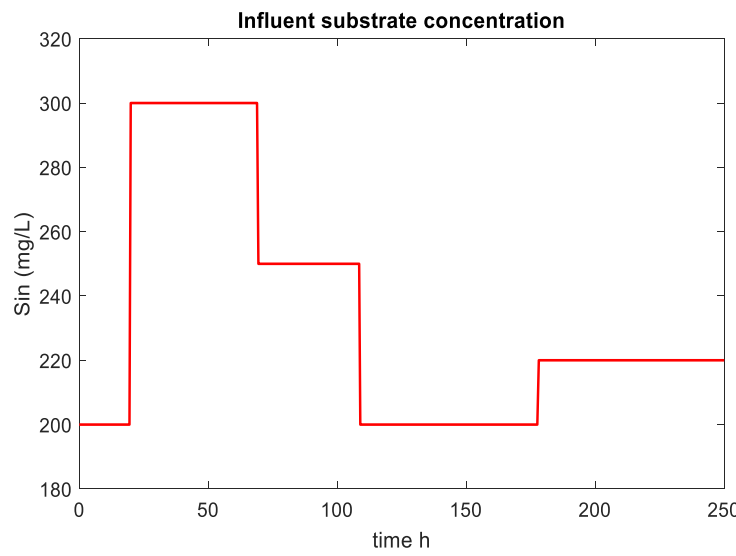

Figure 13. Influent substrate concentration

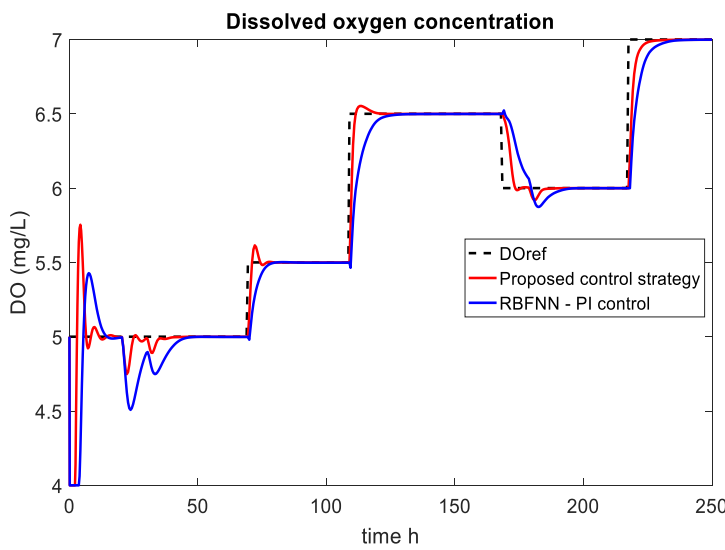

Figure 14. Dissolved oxygen concentration with modified dilution rate and influent substrate 
From Figure 14, when the dilution rate and the influent substrate concentration changed, the RBFNN-PI controller is very affected by these changes and it is not well tracking the set-point reference DOref, contrary of the proposed method that is not very affected by these disturbances generated by dilution rate and the influent substrate concentration. The dissolved oxygen concentration has a good tracking of the setpoint reference DOref by using the proposed control strategy. The aeration rate (control variable) is depicted in Figure 15.

Figure 16, shows clearly that substrate concentration is biologically degraded below the maximum allowable value $20 m g . l^{-1}$.

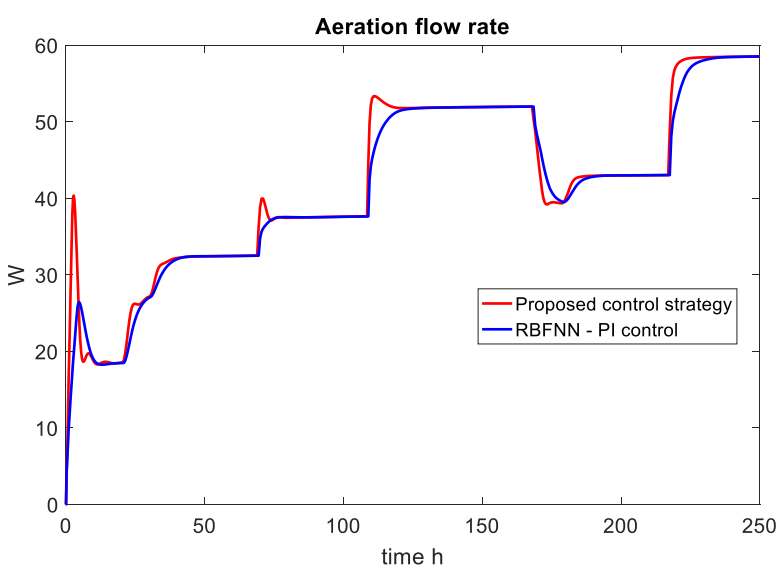

Figure 15. Aeration rate (Control variable)

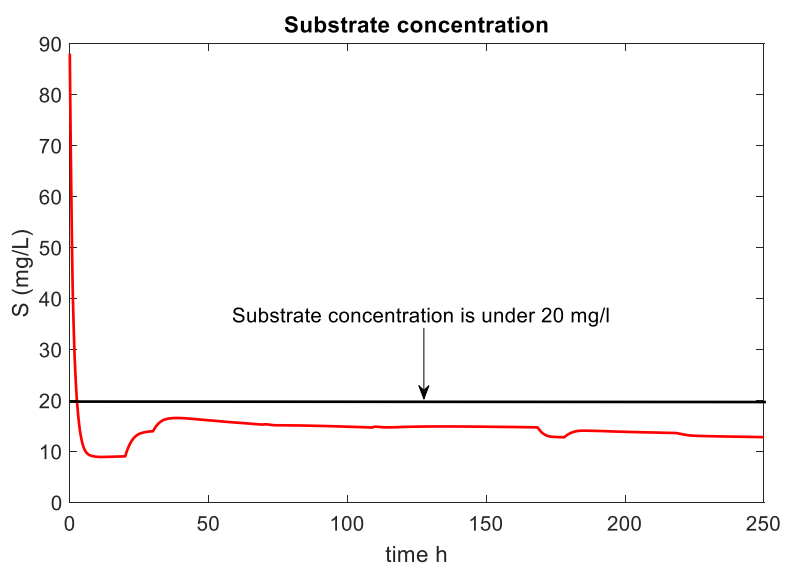

Figure 16. Substrate concentration

The criterions IAE (integral of absolute error) and ISE (integral of square error) are used to compare the performance of the different control strategies:

$$
\begin{aligned}
I A E & =\int_{0}^{\infty}|e(t)| d t \\
I S E & =\int_{0}^{\infty} e(t)^{2} d t
\end{aligned}
$$

The simulations results are compared from the view point of integral of absolute error (IAE). Considering this measure, the dissolved oxygen concentration has the best results applying the proposed controller (Table 1).
Table 1. Simulated IAE and ISE of the controllers

\begin{tabular}{ccc}
\hline Used control methods & IAE & ISE \\
\hline RBFNN-PI controller & 0.1232 & 0.0740 \\
Proposed controller & 0.0678 & 0.0455 \\
\hline
\end{tabular}

\section{CONCLUSION}

In this paper, an Euler control strategy and gradient method based on RBFNN has been established to control the substrate concentration via the control of the dissolved oxygen concentration in an activated sludge process of wastewater treatment. The effectiveness of the proposed method was evaluated through a comparison with RBF neural network PI controller. The simulation results indicate that the proposed control strategy has a better performance for tracking the setpoint reference DOref compared to the RBF neural network PI control.

\section{REFERENCES}

[1] Babuponnusami, A., Muthukumar, K. (2014). A review on Fenton and improvements to the Fenton process for wastewater treatment. Journal of Environmental Chemical Engineering, 2(1): 557-572. https://doi.org/10.1016/j.scitotenv.2019.03.180

[2] Passos, F., Gutiérrez, R., Brockmann, D., Steyer, J.P., García, J., Ferrer, I. (2015). Microalgae production in wastewater treatment systems, anaerobic digestion and modelling using ADM1. Algal Research, 10: 55-63. https://doi.org/10.1016/j.algal.2015.04.008

[3] Mannina, G., Ekama, G., Caniani, D., Cosenza, A., Esposito, G., Gori, R., Olsson, G. (2016). Greenhouse gases from wastewater treatment-A review of modelling tools. Science of the Total Environment, 551: 254-270. https://doi.org/10.1016/j.scitotenv.2016.01.163

[4] Du, X., Wang, J., Jegatheesan, V., Shi, G. (2018). Dissolved oxygen control in activated sludge process using a neural network-based adaptive PID algorithm. $\begin{array}{lll}\text { Applied } & \text { Sciences, } & \text { 8(2): }\end{array}$ https://doi.org/10.3390/app8020261

[5] Holenda, B., Domokos, E., Rédey, Á., Fazakas, J. (2008). Dissolved oxygen control of the activated sludge wastewater treatment process using model predictive control. Computers \& Chemical Engineering, 32(6): 1270-1278. https://doi.org/10.1016/j.compchemeng.2007.06.008

[6] Man, Y., Shen, W., Chen, X., Long, Z., Corriou, J.P. (2018). Dissolved oxygen control strategies for the industrial sequencing batch reactor of the wastewater treatment process in the papermaking industry. Environmental Science: Water Research \& Technology, 4(5): 654-662. https://doi.org/10.1039/C8EW00035B

[7] Liu, D., Zong, X. (2019). Dissolved oxygen control in sewage treatment process based on fuzzy active disturbance rejection control. In 2019 IEEE 3rd Advanced Information Management, Communicates, Electronic and Automation Control Conference (IMCEC), pp. 1164-1168. https://doi.org/10.1109/IMCEC46724.2019.8983931

[8] Han, H., Liu, Z., Qiao, J. (2019). Fuzzy neural networkbased model predictive control for dissolved oxygen 
concentration of WWTPs. International Journal of Fuzzy Systems, 21: 1497-1510. https://doi.org/10.1007/s40815-019-00644-8

[9] Piotrowski, R. (2020). Supervisory fuzzy control system for biological processes in sequencing wastewater batch reactor. Urban Water Journal, 17(4): 325-332. https://doi.org/10.1080/1573062X.2020.1778744

[10] Lin, M.J., Luo, F. (2016). Adaptive neural control of the dissolved oxygen concentration in WWTPs based on disturbance observer. Neurocomputing, 185: 133-141. https://doi.org/10.1016/j.neucom.2015.12.045

[11] Han, H.G., Zhang, L., Liu, H.X., Qiao, J.F. (2018). Multiobjective design of fuzzy neural network controller for wastewater treatment process. Applied Soft Computing, 67: 467-478 https://doi.org/10.1016/j.asoc.2018.03.020

[12] Mirghasemi, S., Macnab, C.J.B., Chu, A. (2014). Dissolved oxygen control of activated sludge bioreactors using neural-adaptive control. In Proceedings of the IEEE Symposium on Computational Intelligence in Control and Automation (CICA 2014), Orlando, FL, USA, pp. 9-12. https://doi.org/10.1109/CICA.2014.7013237

[13] Macnab, C.J.B. (2014). Stable neural-adaptive control of activated sludge bioreactors. In Proceedings of the 2014 American Control Conference (ACC2014), Portland, OR, USA, $\mathrm{pp}$.

4-6. https://doi.org/10.1109/ACC.2014.6858627

[14] Qiao, J.F., Hou, Y., Zhang, L., Han, H.G. (2018)
Adaptive fuzzy neural network control of wastewater treatment process with multiobjective operation. Neurocomputing, 275: 383-393 https://doi.org/10.1016/j.neucom.2017.08.059

[15] Han, H.G., Qiao, J.F., Chen, Q.L. (2012). Model predictive control of dissolved oxygen concentration based on a self-organizing RBF neural network. Control Engineering Practice, 20(4): 465-476. https://doi.org/10.1016/j.conengprac.2012.01.001

[16] Ruan, J., Zhang, C., Li, Y., Li, P., Yang, Z., Chen, X., Huang, M., Zhang, T. (2017). Improving the efficiency of dissolved oxygen control using an on-line control system based on a genetic algorithm evolving FWNN software sensor. Journal of Environmental Management, 187: 550-559. https://doi.org/10.1016/j.jenvman.2016.10.056

[17] Belchior, C.A.C., Araújo, R.A.M., Landeck, J.A.C. (2012). Dissolved oxygen control of the activated sludge wastewater treatment process using stable adaptive fuzzy control. Computers \& Chemical Engineering, 37: 152162. https://doi.org/10.1016/j.compchemeng.2011.09.011

[18] Jeppsson, U., Rosen, C., Alex, J., Copp, J., Gernaey, K.V., Pons, M.N., Vanrolleghem, P.A. (2006). Towards a benchmark simulation model for plant-wide control strategy performance evaluation of WWTPs. Water Sci. Technol, 53(1): https://doi.org/10.2166/wst.2006.031 